\title{
doispontos:
}

\section{A representação política e seus intérpretes: acerca da recepção de Thomas Hobbes}

\author{
Wladimir Barreto Lisboa \\ wblisboa@gmail.com \\ Universidade Federal do Rio Grande do Sul (UFRGS)/CNPq, Porto Alegre, RS, Brasil.
}

\begin{abstract}
Resumo: O artigo pretende analisar dois equívocos na interpretação da representação política em alguns leitores de Thomas Hobbes. Os primeiros buscam, a partir de sua teoria do comando, identificá-lo como um positivista jurídico avant la lettre. Os segundos, ao tentarem resgatar a capacidade de filtrar a lei civil segundo o crivo das leis de natureza, atribuem aos juízes um papel determinante na interpretação dos comandos do poder político. O texto conclui pela crítica a ambas as estratégias de leitura e pela afirmação do cidadão como o último intérprete da autorização que constitui a pessoa artificial.
\end{abstract}

Palavras-chave: Thomas Hobbes; positivismo jurídico; lei civil; lei de natureza; interpretação; pessoa.

\section{The political representation and its interpreters: On the reception of Thomas Hobbes}

\begin{abstract}
The article analyzes two concurrent interpretations of the notion of political representation in the works of Thomas Hobbes. The first one seeks to identify Hobbes as a legal positivist avant la lettre based on his theory of command. The second one goes in the opposite direction and sustains an ability to filter the civil law according to the sieve of the laws of nature, assigning to judges a decisive role in the interpretation of commands. The article criticizes both reading strategies and concludes by affirming the citizen as the final interpreter of the authorization act which constitutes the artificial person.
\end{abstract}

Key-words: Thomas Hobbes; legal positivism; civil law; law of nature; interpretation; person.

\section{APRESENTAÇÃo SUMÁRIA DA FONTE DA REPRESENTAÇÃO POLÍTICA EM HOBBES}

Todos os leitores de Hobbes conhecem em linhas gerais sua teoria da autorização política presente nos capítulos XVI e XVII do Leviatã. Após haver exposto sua concepção da pessoa natural, artificial e a teoria da autorização de seus atos (cap.XVI), o capítulo XVII conclui que a única maneira de construir um poder comum a todos os indivíduos consiste em:

\footnotetext{
designar um homem ou uma assembleia, para assumir sua personalidade; e que cada um concorde e se reconheça como o autor de tudo o que terá feito ou faz, quanto às coisas que concernem a paz e a segurança comuns, aquele que assim assumiu sua personalidade, que cada um, por consequência, submeta sua vontade e seu julgamento à vontade e ao julgamento desse homem ou dessa assembleia. (HOBBES, 2012, p. 177)
}

Uma multidão assim unida em uma só pessoa, prossegue Hobbes, é chamada uma República, em latim Civitas. Assim constituída, essa personalidade é designada como o soberano e possui o poder soberano (summa Potestas). Todo outro homem é seu súdito (Subditi et Cives appellantur) (Cf. HOBBES, 2012, 
p. 263). O soberano tem, desse modo, a autoridade de agir. Sua ação se destina a assegurar isto em razão do que ele foi instituído: uma vida agradável (Cf. HOBBES, 2012, p. 265, 550). O instrumento, o veículo, dessa ação é a lei civil. Por ela o poder político fornece a medida daquilo que é devido e permitido a cada um, a ação justa dos cidadãos não sendo, portanto, senão a observância daquilo que foi previamente consentido como o meio necessário para a paz.

Ademais, para fazer aplicar e interpretar a lei civil, a República, esse animal artificial produzido pela arte do homem, institui os magistrados enquanto prepostos do poder soberano com a função de instituir sua vontade contida em tais leis.

\section{A ALIENAÇÃO DA REPRESENTAÇÃO E O POSITIVISMO JURÍDICO 'AVANT LA LETTRE'}

Ao permanecer nessa exposição sumária e dela fazer uma leitura apressada, muitos comentadores apresentaram a filosofia de Hobbes sob uma perspectiva, a seus olhos, extremamente desfavorável ao filósofo de Malmesbury.

Desse modo, Hobbes seria um positivista jurídico avant la lettre, uma vez que o único critério para identificar a lei civil consistiria na verificação de sua fonte, isso é, se ela foi corretamente significada como um comando do soberano absoluto. Mais, uma vez esses comandos caracterizados como, por definição, justos, uma vez que consentidos, Hobbes seria em seguida apresentado como o precursor de um certo positivismo contemporâneo nomeado como ideológico (Cf. BOBBIO, 1963, p. 110-112) ${ }^{1}$, dado que as leis civis seriam estabelecidas apenas com o propósito de assegurar o único valor essencial expresso na exigência de manutenção de uma ordem válida, a saber, a obediência.

Em seguida, prosseguindo com essa leitura que atribui a Hobbes um positivismo avant la lettre, tratar-se-ia de mostrar seus sucessores na "família" positivista. Hobbes é então exibido como estando na origem de certas teses de dois autores que são correntemente associados como seus herdeiros na construção de um projeto de identificação das normas válidas a partir das noções de comando, ameaça, obediência e, finalmente, independência desses mesmos comandos a padrões de correção moral externos à lei positiva. Trata-se aqui de Jeremy Bentham (BENTHAM, 1970) e John Austin (AUSTIN 1832/1995)22.

O problema com essas interpretações, segundo alguns scholars contemporâneos que, como Dyzenhaus (DYZENHAUS, D ${ }^{2012)}$, procuram extrair a melhor interpretação dos textos do filósofo de Malmesbury, é que essas leituras são redutoras do pensamento de Hobbes dado que se apoiam em uma análise equivocada do papel das leis de natureza em sua teoria política. Esse papel não poderia ser unicamente o de identificar a fonte da normatividade jurídica ${ }^{3}$, isso é, após haver assegurado a obediência civil, as leis de natureza eclipsar-se-iam diante da omnipotência da lei civil (Cf. LLOYD, 2009, p. 280)4. Ao contrário, bem compreendida, a teoria da autoridade jurídica deixaria um lugar preponderante às leis de natureza na determinação do conteúdo das leis civis ao conferir a estas uma moralidade constitucional. ${ }^{5}$ Quando as partes submetem uma disputa a um árbitro, afirma Dyzenhaus, elas o fazem não apenas na esperança de que ele dará uma decisão final, mas também na expectativa de que a decisão estará em conformidade com o conteúdo das leis de natureza que estabelecem uma disciplina moral ao papel do árbitro. Um bom juiz, então, é aquele que, na interpretação da lei escrita, faz repousar sua compreensão na lei não escrita, nas leis de natureza (Cf. DYZENHAUS, D. 2012, p. 196). 
Um dos propósitos desse artigo consistirá em apresentar de que modo o fundamento de tal estratégia de valorização do papel das leis naturais em Hobbes, e sua aplicação no discurso jurídico contemporâneo, corre o risco de dissolver a unidade da representação política na figura do soberano, na medida em que ela cria uma fonte quase autônoma na produção de lei civil, a saber, os juízes.

\section{A RELAÇÃO ENTRE LEI NATURAL E LEI CIVIL EM HOBBES}

Tal valorização do papel das leis de natureza, entretanto, leva o texto hobbesiano um pouco longe, até o ponto de conferir-lhe a aparência de um autor que sustentaria uma espécie de moralidade como condição mesma de manutenção da juridicidade das leis no tempo. Ao fazer isso, produz-se uma distorção da representação política na medida em que é dado aos juízes um papel que ultrapassa o da interpretação da lei civil e os transforma em fonte autônoma de autoridade na determinação da concordância dessas leis, segundo seu conteúdo, com as leis de natureza, o que coloca esses mesmos juízes fora do controle do poder político soberano.

Evidentemente, há bases textuais claras para sustentar essa submissão da lei civil. Tomemos a seguinte passagem de Hobbes: "Assim, se ele [o soberano] institui um juiz, é preciso que este preste atenção ao fato de que sua sentença deve estar de acordo com a razão de seu soberano: e esta sendo sempre reputada coincidir com a equidade, ele está vinculado a esta pela lei de natureza" (HOBBES, 2012, p. 524). Hobbes crê que os juízes subalternos têm o dever, diante do soberano, de interpretar as leis civis como estando em conformidade com as leis de natureza, pois pensar o contrário "seria, da parte de um juiz, uma grave contumélia" (HOBBES, 2012, p.436).

Sob essa base, um autor como Dyzenhaus deduz que os juízes deveriam declarar as leis como juridicamente inválidas toda vez que sua interpretação se revelasse contrária às leis de natureza. Esse dever é o que o autor chama condição de legalidade (legality provisio), isso é, as leis do soberano devem ser interpretadas à luz das leis de natureza (Cf. DYZENHAUS, 2012, p. 199, 207). Essa condição de legalidade colocaria limites à autoridade soberana em relação a seus súditos. Haveria uma exigência da parte da lei civil de satisfazer uma certa moralidade interna do direito (Cf. DYZENHAUS, 2001, p. 491) ${ }^{6}$. Enfim, pareceria que a equidade exigiria o respeito a "algo como um modesto igual direito material substantivo ao mundo e a seus recursos" (Cf. DYZENHAUS, D. 2012, p. 170).

Passemos agora à analise dessas teses. Primeiramente, "um modesto igual direito material substantivo" encontra-se em contradição com a noção de Hobbes segundo a qual não existe um mérito natural que uma certa justiça distributiva devesse respeitar. Se determinada atribuição equânime fornece um resultado igual, isso não se deve a que a equidade exige uma igualdade substantiva, mas porque um procedimento correto pode produzir esse resultado. Ademais, é bem verdade que os juízes devem interpretar a lei civil segundo a equidade, mas eles não podem rejeitá-la como não estando conforme a equidade, o que acarretaria $o$ absurdo em que "o intérprete tornar-se-ia o legislador." (HOBBES, 2012, p. 428). A solução de Hobbes consiste em pensar o soberano como juiz supremo, tendo a oportunidade de reformar um julgamento não equânime junto à Corte de Equidade (HOBBES, 2005, p. 25). Pensar o contrário seria negar a afirmação de Hobbes segundo a qual não é a sabedoria, isso é, a razão artificial de juízes subalternos, que faz a lei, mas a autoridade do soberano. Mas o que fazer então da exigência de interpretar segundo a equidade? Como combinar a interpretação segundo a equidade e o respeito à lei civil?

A primeira coisa a reter nesse ponto é que "o juiz do correto e incorreto não é, ao mesmo tempo, juiz daquilo que é cômodo ou incômodo à República” (HOBBES, 2012, p. 438). Nenhuma incomodidade, prossegue Hobbes, pode autorizar uma sentença contrária à lei civil. Ou seja, a incomodidade resultante 
do texto material pode enviá-lo à intenção da lei, à sua melhor interpretação, mas jamais à sua ab-rogação. Não se trata aqui de construir uma teoria omnipotente do legislador concebido segundo o pressuposto de que um juiz autômato teria todo o material necessário para decidir um caso cuja solução estaria já previamente prevista e configurada na lei. O problema colocado para Hobbes, creio, consistia em pensar a construção de um poder político, e a paz que se lhe segue, em que as instituições assegurariam a subordinação dos juízes à lei soberana, apesar, evidentemente, desta não poder prever todas as situações empíricas e, portanto, dar respostas adequadas a cada caso de aplicação da regra.

A precaução política a tomar aqui consiste em não conceder aos juízes o poder de modelar a expressão da lei, pois isso reforçaria a concepção segundo a qual seus deveres enquanto juízes não são o de decidir conforme a lei, mas o de fazer justiça, dar a cada um o que lhe é devido, ainda que utilizando a lei como guia. Sobre essa suposição, dissolver-se-ia a ideia segundo a qual a distinção entre o legislador e o juiz é institucionalmente produzida. E ela é produzida por decisão da soberania: "Aqueles a quem é conferida a jurisdição são ministros públicos. Com efeito, em sua jurisdição eles representam a pessoa do soberano, e sua sentença é a sentença do soberano" (HOBBES, 2012, p. 380).

Poderíamos ilustrar esse ponto recorrendo a uma citação de Montesquieu. ${ }^{7}$ Este desvio será feito porque acredito que a argumentação desenvolvida nesse texto esclarece o propósito de Hobbes. Trata-se de uma passagem que se tornou o slogan contra o qual se batem todos os que buscam conformar as disputas jurídicas a uma normatividade que estaria para além da lei civil. Entretanto, Montesquieu tinha razão. Diz ele:

Poderia ocorrer que a lei, que é ao mesmo tempo clarividente e cega, fosse, em certos casos, excessivamente rigorosa. Mas os juízes da nação não são, como dissemos, senão a boca que pronuncia as palavras da lei; seres inanimados que não podem moderar nem sua força nem seu rigor. É, assim, a parte do corpo legislativo, que acabamos dizer ser, em outra ocasião, um tribunal necessário, que o é ainda nessa ocasião; cabe à sua autoridade suprema moderar a lei em favor da lei ela mesma, pronunciando-se menos rigorosamente que ela. (MONTESQUIEU, 1995, p. 337-38)

Montesquieu está analisando aqui os princípios de exceção à separação dos poderes. A segunda exceção de que se trata nessa passagem supõe justamente que no direito não há, para todas as circunstâncias, uma resposta que pudesse ser mecanicamente aplicada pelos juízes. Retomemos a frase de Montesquieu: "Poderia ocorrer que a lei, que é ao mesmo tempo clarividente e cega, fosse, em certos casos, excessivamente rigorosa”. Analisemos a razão pela qual a lei é cega. Para isso, retornemos ao texto de Hobbes no capítulo XXVI, justamente onde ele analisa um caso de exceção à aplicação de uma regra julgada excessivamente rigorosa. A lei civil apresentada por Hobbes prevê que: "Aquele que for expulso de sua casa pela força, a ela seja reintegrado pela força” (HOBBES, 2012, p. 436). A lei é cega no sentido de que se trata, para o juiz, de simplesmente analisar se a força foi empregada para a expulsão e se se trata de sua casa, isso é, analisar se estão verificados no caso presente as hipóteses previstas na regra e aplicar as consequências normativas. Mas, dizia Montesquieu, a lei é cega e clarividente ao mesmo tempo. É porque a sociedade não pode tolerar uma violação tão grave da propriedade que se faz necessário reintegrá-la pela força. A República não pode permitir a resolução do conflito por uma disputa de força entre as partes. A cegueira e a clarividência da lei são a mesma característica, a saber, sua formalidade: a exclusão, no enunciado normativo, de tudo aquilo que não possui relevância e que, desse modo, permite a resolução do conflito. Com efeito, querer que cada caso jurídico reclame novas considerações devidas a sua particularidade imporia aos juízes uma perquisição quase infinita e tornaria o direito um fábrica de incoerências. A formalidade desempenha o papel de garantir que casos semelhantes tenham uma decisão semelhante.

Se assim é, o que quer Montesquieu dizes quando afirma que essa lei cega e clarividente não pode ser excessivamente rigorosa? Ora, a lei tem necessidade de ser moderada não porque seria mais justo fazê-lo, em cujo caso estaríamos procurando o justo simpliciter, mas ela deve ser moderada em favor da própria lei. 
No exemplo de Hobbes, a hipótese é de que "pode ocorre que um homem, por negligência, deixe sua casa desocupada e que, ao seu retorno, seja impedido de entrar mediante força” (HOBBES, 2012, p. 436). A lei é excessivamente rigorosa porque o que ela não vê é que se trata aqui de um caso que difere dos pressupostos da lei, mas que poderia ter sido pensado pela lei. O que essa lei não prevê em suas hipóteses é o caso em que se trate de uma grave violação pela força de uma propriedade de alguém que não foi expulso pela força. A presunção da lei deve ser moderada ou ampliada em sua extensão não porque ela faz uma suposição injusta, mas porque dizer desse caso que ele não é o caso da lei é contrário à lei mesma. A lei deve ser moderada pela lei mesma. No caso de Montesquieu, trata-se de enviar a questão ao legislador não para modificar ou ab-rogar a lei, o que não constituiria um ato de realizar uma exceção, mas a própria atividade do legislador. $\mathrm{O}$ espírito das leis é que sua moderação é uma atividade propriamente jurisdicional, apesar de ser conduzida, no caso de Montesquieu, pelo legislativo. Assim se constitui a exceção! Tratando-se de Hobbes, creio ser possível afirmar que, como Montesquieu, todo o problema consiste em dar uma forma institucional à ideia de que a lei civil vale enquanto declaração de uma vontade política. Não se trata, portanto, de uma questão de razão em que caberia aos juízes conhecerem o sentido da lei apenas pela reflexão, independentemente da vontade do soberano. $\mathrm{O}$ ato do juiz que declara a interpretação a ser dada à lei no momento de sua aplicação é uma declaração de vontade que deve se reportar sempre a uma vontade já declarada, a saber, aquela do poder político.

Ora, querer atribuir aos juízes o papel de determinar o que é devido a cada um acima ou além da lei civil é o mesmo que dizer que uma lei apenas é efetiva na medida em que for justa ou, o que advém ao mesmo, na medida em que ela estiver em harmonia com os direitos fundamentais. ${ }^{8} \mathrm{O}$ direito moderno, ao contrário, à diferença do direito pré-moderno, vê a irrupção da figura do legislador soberano que cria conscientemente novas normas jurídicas. Um sistema pré-moderno, ou não moderno, é um sistema que faz apelo às práticas tradicionais ou à "natureza das coisas" para decidir o que é devido a cada um. Todavia, a tradição, a história ou a arte dos juízes não pode evitar os desacordos políticos dos indivíduos. Tais desacordos não podem ser resolvidos por um apelo às opiniões privadas ou por referência a uma autoridade moral independente da República. A pretensa sabedoria prática de uma elite de juízes não garante uma via epistemologicamente privilegiada ao justo.

Assim, querer converter a lei natural em critério de eficácia da lei civil equivale a promover o jus, o que é devido, à noção central do direito. Substituir as noções de obrigação, direitos, deveres, etc., que individualizam as posições e recortam o espectro a partir do qual o juiz deve decidir, por uma outra noção fluida dos direitos, como atestando uma equidade encontrada a partir da submissão do conteúdo material da lei civil à afirmação do bem ou do conveniente, fazer essa afirmação, dizia, equivale a tornar a ordem jurídica inoperante e relegada, em definitivo, à esfera das facções políticas.

\section{4. É PRECISO RESTITUIR A REPRESENTAÇÃO POLÍTICA À SOBERANIA E É NECESSÁRIO MANTER A VERDADEIRA LIBERDADE}

A teoria da "condição de legalidade" (legality proviso) de Dyzenhaus apresentada acima tem o mérito de indicar o erro de interpretar-se a noção de autoridade política em Hobbes como estando fundada em uma relação simples de comando endereçado aos indivíduos mediante a ameaça de sanção em caso de desobediência. Seguindo-se essa interpretação equivocada, pareceria que aos cidadãos resta apenas secundar para sempre os comandos de uma autoridade absoluta. $\mathrm{O}$ ato irrevogável de instituição do poder político, ao assegurar ao soberano o monopólio da criação da lei civil, deixaria aos indivíduos desse modo alienados apenas a tarefa de obedecer pelo medo da espada. 
Entretanto, como corretamente mostrou Dyzenhaus, Hobbes, à diferença de Bentham e Austin, não define a lei civil como um comando sustentado por ameaça. Ela também não se constitui como um comando endereçado por alguém a não importa quem, "mas o fato apenas daquele cujo comando dirige-se a um homem previamente obrigado a obedecer-lhe. E não há mais nada na expressão da lei civil senão a menção da pessoa que ordena, que é a persona civitatis, a pessoa da República" (HOBBES, 2012, p. 414). Fica claro, desse modo, que a força dos comandos da República repousa sobre uma obrigação prévia que deve sua origem justamente ao momento de constituição dessa persona civitatis.

Todavia, o equívoco de Dyzenhaus, parece-me, consiste em expandir excessivamente a representação política ao atribuir aos juízes uma função que eles não podem possuir, a saber, a de subordinar a lei civil ao filtro das leis de natureza. A condição de legalidade (legality proviso), diz Dyzenhaus, ensina-nos que não é suficiente, para uma lei positiva qualquer, que ela realize tudo o que é requerido enquanto critério público para sua existência, como, por exemplo, que ela seja significada por sinais adequados, mas é necessário ainda que ela seja interpretada pelos juízes à luz das leis de natureza (DYZENHAUS, 2012, p. 199).

Recolocando a questão, retornemos ao texto de Hobbes a propósito da constituição da persona. Essa análise permitirá discernir corretamente os direitos e deveres daqueles que estão concernidos na constituição da Civitas". Diz Hobbes: "É uma pessoa aquele cujas palavras ou ações são consideradas como suas ou como representando as palavras ou ações de um outro homem ou de uma outra coisa à qual elas são atribuídas, de modo verdadeiro ou por Ficção".

Assim, uma pessoa age (e as palavras são também ações) em nome próprio ou em nome de um outro homem ou de uma coisa. As ações são consideradas, isso é, são tomadas sob o modo da imputação. Como sinais exteriores, os aprendemos e designamos os possuidores da ação. Há a ação, aquele que age e aquele em nome de quem se age. A ação pode ser imputada àquele que age, a um terceiro ou à alguma outra coisa. A ação pode, portanto, não ser atribuída àquele que manifesta a ação, ela pode não ser considerada como sua. Quando a ação é atribuída a alguma coisa ou a alguém que não pode verdadeiramente possui-la, dizemos que sua atribuição é uma ficção, como é o caso, por exemplo, para um animal, uma criança, um louco, um hospital ou uma coisa inanimada. Prossegue Hobbes: "Quando elas [as ações] são consideradas como suas, ela [a pessoa] se chama Pessoa Natural. E quando elas são consideradas como representando as palavras e ações de um outro, então trata-se de uma Pessoa por simulação [feigned] ou artificial." Simulação, nesse contexto, corresponde ao fato de que a atribuição da ação que se realiza no mundo, desde o ponto de vista de sua verdadeira agência, pertence a um outro e, assim, exige uma suposição, um artifício da parte daquele que a considera. Mas isso não impede que a atribuição seja verdadeira. Desse modo, prossegue Hobbes, "Uma Pessoa é a mesma coisa que um Ator em cena ou nas relações ordinárias. E personificar é Agir, ou bem Representar a si mesmo ou um outro, e aquele que age por um outro é dito portar sua pessoa ou agir em seu nome". $\mathrm{O}$ ator, assim, representa um personagem porque sua ação não é a dele, mas representa as ações de alguém doutro, como no teatro. Aqui, quando o personagem, por exemplo, grita, há aí um som que sai da boca do ator. Mas esse grito não pertence ao ator. Ele é o grito do personagem em nome de quem ele atua. Ele deve ser compreendido como substituindo uma ausência: o grito daquele que ele representa. Ele presentifica, se podemos dizer, uma ausência.

Concluiremos essa apresentação da teoria da constituição da pessoa em Hobbes com uma passagem que é decisiva para nossa hipótese de trabalho. Trata-se da introdução da noção de autoridade. Diz Hobbes no mesmo capítulo XVI:

As palavras e as ações de certas Pessoas Artificiais são possuídas por aqueles que elas representam. A Pessoa é então o Autor, e aquele que possui suas palavras e ações é o Autor, em cujo caso o Ator age por Autoridade (...) e do mesmo modo que o direito de possuir é chamado Propriedade, o Direito de fazer uma ação é chamado Autoridade. 
Assim, por autoridade compreendemos sempre um direito de fazer uma ação qualquer, e por Feito sob autoridade, compreendemos feito por mandato ou permissão da parte daquele que tem o direito. (HOBBES, 2012, p. 244)

O mandatário, isso é, a representação enquanto instituída de autoridade, emana desse direito a agir que foi transmitido de um autor a um ator. Esse último, por sua vez, age no limite do que lhe foi mandatado. Finalmente, o ato de instituição de um representante político (o maior de todos os poderes) ocorre quando o maior número possível de homens autoriza, pelo consentimento, a criação "desse grande Leviatã que chamamos República ou Common-Wealth (Civitas em latim), o qual não é senão um homem artificial, ainda que de uma força maior do que aquele homem natural, para cuja defesa e proteção ele foi concebido" (HOBBES, 2012, p. 16). ${ }^{11}$

A defesa e a proteção são, portanto, os termos da autorização. Uma assembleia ou um homem serão designados para assegurar a pessoa de uma multidão. A República torna-se assim uma pessoa porque ela age por representação. Consequentemente, "dado que o objetivo dessa instituição é a paz e a defesa de todos, e que quem tem o direito ao fim tem o direito aos meios, pertence de direito a todo homem ou assembleia investida de soberania ser juiz ao mesmo tempo dos meios necessários à paz e à defesa" (HOBBES, 2012, p. 270). Ora, para a paz é necessário que sejam instituídas regras comuns que distingam o correto do incorreto. Enquanto leis da cidade, tais regras serão o veículo de um comando endereçado a indivíduos previamente obrigados a obedecer à pessoa da República: o soberano é o único legislador (Cf. HOBBES, 2012, p. 270).

Os cidadãos estão previamente obrigados a obedecer porque convieram acerca da incomensurabilidade de seus interesses, isso é, eles sabem que o acordo sobre o bem e o justo, sem a lei civil, é impossível. Eles aceitam assim seguir um comando mesmo que esse seja contrário a seus interesses. As vontades dos cidadãos, desse modo, não são subsumidas na vontade do poder político: eles aceitam fazer aquilo que eventualmente não quereriam fazer, mas que, não obstante, se engajaram a fazer.

O que é preciso reter aqui é que os cidadãos mantêm sempre a diferença entre suas vontades e as do soberano. E isso deve ser assim, pois a instituição de um poder absoluto é o único ato que pode garantir a paz. Trata-se aqui de um ato voluntário, e o objeto dos atos voluntários é sempre, segundo Hobbes, um bem para aquele que age. Ora, justamente porque se trata de um ato voluntário, não seria racional para os indivíduos aceitar a vontade do poder político como sendo a sua. É preciso sempre atentar, pois "existem certos direitos tais que não podemos conceber que algum homem os tenha abandonado ou transmitido por quaisquer palavras que sejam ou por outro sinal" (HOBBES, 2012, p. 202). ${ }^{12}$ Se é assim, podemos dizer que os cidadãos serão sempre intérpretes legítimos das leis civis, pois advém sempre a eles apreciar a compatibilidade entre essas leis e a finalidade pela qual a República foi instituída. Uma vez violados esses direitos que não podem ser transmitidos, a resistência torna-se legítima. Os indivíduos são legítimos intérpretes dos atos da pessoa civitatis. E eles o são por considerações que são externas à lei civil (seus direitos inalienáveis).

Resta-nos examinar, com novos argumentos, se os juízes podem legitimamente ser a segunda instância interpretativa da lei civil. E isso em um sentido bem preciso: podem eles considerar sua validade pela consideração de um critério (o legality proviso) que seria, como era o caso para os cidadãos, ele também exterior à lei da cidade?

A primeira observação a fazer é que, se as leis de natureza possuíssem a capacidade de individuar aquilo que é devido a cada um, então a autoridade da lei civil desapareceria. Evidentemente, as leis de natureza têm uma função precisa na ordem jurídica, a saber, a de indicar o caminho a tomar na edificação da ordem 
política. Elas nos mostram qual desenho institucional é preciso construir e quais são suas finalidades. Assim, justamente, dado nosso desacordo, na ausência de um poder político, acerca do justo, as leis de natureza impulsionam ao esforço de criar um ator e a conceber os instrumentos de sua ação: os comandos. À lei civil pertence a tarefa de individuar isso que é devido a cada um. Em resumo, a explicitação da finalidade da vida civil impõe uma certa teoria sobre o significado da paz, do poder político, de seus direitos, deveres, etc. Esses são valores a partir dos quais é construída a instituição política. Ao estabelecer a lei civil como instrumento da ação política, a soberania realiza sua função mediada pela lei civil. Ora, dizer que a lei civil apenas pode ser limitada pela lei civil, como foi mostrado acima, reforça a afirmação de que, exatamente nesses limites ela realiza justamente o que demanda a equidade: tratar os cidadãos de modo igual através da forma da lei. O que torna possível realizar a equidade é justamente o fato de que ela se individualiza pela institucionalização de um Estado que age através da lei civil. Portanto, o que torna credível a moralidade expressa nas leis de natureza não é o fato de se mensurar cada ato público pelo filtro da equidade, mas o fato de que, atribuindo a cada um seu devido, pela lei civil, efetiva-se a justiça. A tese de Dyzenhaus, se ela tem o mérito de valorizar corretamente a noção de obrigação suposta na justificação da validade do comando, presta-se a sobrevalorizar o papel dos juízes na interpretação da lei civil. Seu argumento, longe de se restringir a casos limites, é hiperbólico e atinge a estrutura mesma da representação política. $\mathrm{O}$ argumento fracassa porque concebe os atos dos juízes como os de uma simples declaração de vontade, o que absolutamente não está implicado na autorização da representação política. É claro que os juízes devem interpretar a lei civil. Mas, para afirmar mais uma vez, essa interpretação jamais pode ser filtrada por um critério que lhe seja externo. Aplicar a lei é realizar a justiça, realizar a justiça é efetivar a finalidade das leis de natureza. A finalidade cria a República, a República atribui a cada um seu devido. Finalmente, como o diz Hobbes no Leviatã latino: "Em uma mesma cidade, as leis de natureza e as leis civis contêm-se umas às outras” (HOBBES, 2012, p. 419).

\section{NOTAS}

1. Bobbio, todavia mitiga sua posição às páginas 115-116: "Anche nel sistema hobbesiano, in cui è giusto ciò che è comandato dal sovrano, la ragione dell’obbedienza viene meno quando le leggi, invece di assicurare la realizzazione del fine per cui sono state poste, la protezione della vita individuale, lo mettono a repentaglio."

2. O propósito aqui consiste em remarcar a rapidez com que Hobbes é primeiramente tomado como precursor do positivismo contemporâneo para, a seguir, ser exibido como o ancestral comum de uma "família" que prossegue com Bentham e Austin. Para uma análise crítica dessa filiação, ver DYZENHAUS, 2012; CRIMMINS, JAMES, 2002; HART,1982.

3. Sobre o argumento da perda da função normativa das leis de natureza em Hobbes, ver Bobbio, 1963, p. 130-131.

4. Na página 280 ela prossegue: "Once we see this, the self-effacing character of Hobbes's natural law theory is guaranteed. There is no sense to be given to the idea that we should disobey the sovereign's declarations of positive law on the ground that in our judgment they conflict with the natural law."

5. Haveria mesmo, segundo Dyzenhaus, uma espécie de moralidade constitucional inerente à ordem jurídica. Cf. DYZENHAUS, 2012, p. 193: "These laws, derivable from the right of nature, play a role in the legal order of a civil society since they are a kind of constitutional morality intrinsic to legal order."

6. A referência aqui é evidentemente a Fuller, 1977, para quem a ordem jurídica não se confundiria com a simples estabilidade, mas constituir-se-ia em um modo particular de obter-se uma ordem com sua própria moralidade interna ou institucional.

7. Retomo aqui o exemplo e a análise feita por Fernando Atria, adaptando-a ao caso de Hobbes. In Atria, F. La forma del derecho, livro ainda inédito. Agradeço ao autor a disponibilização do texto antes de sua publicação. 
8. A expressão direitos fundamentais, nesse contexto, significa a remissão ao imemorial ou a algo que está para além do poder civil, como se verá a seguir.

9. Ver-se-á igualmente que a exposição sumária da teoria da Pessoa apresentada no início desse artigo pode ser utilizada, como de fato o foi por diversas vezes, para dar do pensamento de Hobbes uma interpretação contrária a seu prórpio texto.

10. Essa tradução e as seguintes do capítulo XVI do Leviatã são propostas por Milanese, in MILANESE, 2011, p. 322 e seg.

11. Tradução ligeiramente modificada.

12. Com efeito, não seria um ato voluntário abandonar o direito a todos os meios de preservar nossa vida ou a daqueles “cuja condenação colocaria o homem na miséria: um pai, uma esposa, um benfeitor.” (HOBBES, 2012, p. 214).

\section{REFERÊNCIAS BIBLIOGRÁFICAS}

AUSTIN, John. 1832/1995. The Province of Jurisprudence Determined. W. Rumble, ed., Cambridge: Cambridge University Press.

BENTHAM, Jeremy. 1970. Of laws in general. Ed. by H. L. A. Hart. London : University of London, The Athlone press.

BOBBIO, N. 1963. Giusnaturalismo e positivismo giuridico. Milão: Edizzioni di Comunità.

CRIMMINS, J. E. 2002. Bentham and Hobbes: An Issue of Influence. Journal of the History of Ideas, Vol. 63, No. 4, pp. 677-696.

DYZENHAUS, D. e Poole, T. 2012. Hobbes and the Law. Cambridge: Cambridge University Press.

DYZENHAUS, D. 2001. Hobbes and the Legitimacy of Law. Law and Philosophy, Vol. 20, No. 5 (Sep., 2001), pp. 461-498.

DYZENHAUS, D. 2012. Hobbes on the authority of law, In Dyzenhaus, D. et Poole, T. Hobbes and the Law. Cambridge, Cambridge University Press,

FULLER, Lon. 1977. The morality of law. Yale: Yale University Press.

HART, H. L. A. 1982. Essays on Bentham. Oxford: Oxford University Press.

HOBBES, T. 2012. Leviathan, or The Matter, Forme, \& Power of a Common-Wealth Ecclesiasticall and Civill. Ed. by Noel Malcolm. Vol. 2. Oxford: Oxford University Press.

HOBBES, T. 2005. Writings on Common Law and Hereditary Right. Oxford: Clarendon Press.

LLOYD, S. A. 2009. Morality in the philosophy of Thomas Hobbes. Cases in the law of nature. Cambridge : Cambridge University Press,.

MILANESE, A. 2011. Principe de la philosophie chez Hobbes. L'expérience de soi et du monde. Paris : Classiques Garnier.

MONTESQUIEU, 1995. De l'Esprits des lois. Paris, Folio Essai, I, livre XI, chap. VI, De la Constitution d'Angleterre, p. 337-38. 